\title{
Children's Resource Shares: Male Versus Female-Headed Households
}

\author{
Theophiline Bose-Duker ${ }^{1} \cdot$ Michael Henry ${ }^{1} \cdot$ Eric Strobl $^{2}$ (])
}

Accepted: 26 November 2020 / Published online: 5 December 2020

(c) The Author(s) 2020

\begin{abstract}
This is a comparative study of children's resource shares in male-headed and female-headed households. To this end we estimate a household collective model using a rotating panel of households from the Jamaican Survey of Living Conditions over a period of 21 years (1990-2010). We find that the gender of the household head is important in determining individual resource shares within the household. Our results also indicate that children receive substantially larger resource shares in female-headed households than in male-headed ones and hence children who live in relatively poor female-headed households are not necessarily worse off. Additionally, the effects of household characteristics on the shares of children are shown to vary considerably based on the gender of the household head.
\end{abstract}

Keywords Children's resource shares $\cdot$ Female-headed households $\cdot$ Collective model $\cdot$ Jamaica

\section{Introduction}

It has long been recognized that family structure may play an important role on the socio-economic status of the household and its members (see Jeynes 2002). In this regard the growing incidence of female headship of households across the world has motivated considerable policy research because of its link to poverty, gender inequality, and child welfare. A recent study by the United Nations (2017) estimates the proportion of female-headed households (FHHs) to be $34 \%$ in Latin America and the Caribbean, 27\% in Africa , and $19 \%$ in Asia. Importantly, it has been argued widely that, compared to male-headed households (MHHs), FHHs are likely to be poorer and more vulnerable as women tend to have less access to productive resources such as land and capital (Buvinic and Gupta 1997), credit (Zeller et al. 1997), and receive lower wages compared to men for similar jobs

Eric Strobl

eastrob113@gmail.com

Theophiline Bose-Duker

theophiline.duker@gmail.com; txb379@bham.ac.uk

Michael Henry

m.henry.1@bham.ac.uk

1 Department of Economics, University of Birmingham, Birmingham, UK

2 Department of Economics, University of Bern, Bern, Switzerland
(Boxill and Quarless 2005). For instance, the United Nations Development Programme (2005, pp. 299-308) estimates that women in Latin America and the Caribbean earn only $40 \%$ of men's incomes in USD (2003 PPP). This implies that FHHs are more likely to raise children with lower health and educational outcomes, leading to lower labour market outcomes in the long run (Handa 1994). On the other hand, the general consensus in the literature is that the preferences of women tend to favour children, where studies such as Duflo (2003), Duflo and Udry (2004), and Caiumi and Perali (2015) have shown that women spend more on child-related goods such as food, health and education, while men spend more on adult-specific goods, such as tobacco and alcohol. Hence, in FHHs, and in single-mother households in particular, the well-being of children may increase as a result of higher expenditure on child-friendly goods. Since both arguments are equally plausible, the actual impact of female headship on child welfare in specific contexts can only be determined empirically.

This study further addresses the issue of female headship and child welfare by investigating the relationship between the gender of the household head and the nature of intra-household resource allocation towards children using a modern collective household model in the context of Jamaica. The basic idea behind this approach is to compare the spending on goods that are separably consumed, but still comparable, by adults and children within a household. To the best of our knowledge our paper is the first to compare 
FHHs to MHHs within this framework. More precisely, the few existing studies that have investigated whether children are better or worse off in FHHs have done so by comparing expenditure on goods or individual outcomes that are not strictly individually assignable, not consumed by both adults and children, or are not strictly comparable even if consumed by both. For example, while Johnson and Rogers (1993) showed that children in FHHs were at least as well nourished as those in MHHs, one cannot conclude explicitly from this that adults in FHHs have a stronger preference for allocating resources towards children than MHHs. Although other more recent literature has instead focused on intrahousehold allocation and found that women and children tend to be poorer than men living in the same household (Dunbar et al. 2013; Mangiavacchi et al. 2014), these papers have only focused on MHHs. Here we instead estimate the resource shares allocated to adults and children within MHHs and FHHs.

Jamaica is arguably an interesting test case for the analysis at hand since it has one of the highest incidences of FHHs in the world. According to an executive summary of the 2012 Jamaican Survey of Living Conditions, $45.6 \%$ of all households in Jamaica are female-headed, with $26 \%$ of these households containing a male-adult resident. ${ }^{1} \mathrm{~A}$ high percentage of FHHs usually indicates a matrifocal society (Safa 2007). In fact, various sociological and anthropological studies have established the central role women and mothers play in Jamaica and the Caribbean society at large (Massiah 1983; Sargent and Harris 1992; Stuart 1996). Relatedly, the Caribbean is also known for its weak conjugal bonds, strong consanguineal ties, and unconventional mating and residential patterns. ${ }^{2}$ Additionally, most young adults in Jamaica tend to engage in visiting relationships and have children before they enter a residential union, such as a common law relationship ${ }^{3}$ or marriage (Handa 1996a; Eggleston et al. 1999). These mating patterns usually force young women to become the sole breadwinner for the household in the absence of a male adult. In contrast to this, there are also women who willingly choose to be household heads as an adaptive response to local economic conditions, including high rates of male unemployment, increasing female

\footnotetext{
${ }^{1}$ Partnered FHHs usually result when a man is unable to provide financially for his family, is away seeking job opportunities (Massiah 1982) or when the household lives in a property owned by the woman (Handa 1996a).

2 According to Massiah (1983) and Safa (1998),these weak conjugal unions originated during the slave trade as married slaves were usually sold separately. Mothers and children were, however, sold together creating strong consanguineal ties between mothers and children.

${ }^{3}$ A common law relationship exists when a couple share a residence but is not legally married.
}

participation rates (Handa 1996a; Safa 1998), and a high rate of emigration of male adults (Massiah 1982). They thus take advantage of male absenteeism to secure their own welfare and that of their children, and to maintain their independence and the custody of their children.

Jamaica has been the subject of a number of previous studies on FHHs (e.g., Handa 1994, 1996c, 1998; Louat et al. 1993). Whereas Handa (1996a) attempted to identify the economic factors that lead to the formation of FHHs in Jamaica using a bargaining model of headship choice, Louat et al. (1993) and Handa (1994) evaluated the relationship between gender, headship and child welfare using reduced form regressions. Their findings indicated that children raised in FHHs were not necessarily disadvantaged when compared to children in MHHs with similar characteristics. This was supported by Handa (1996b) who found that FHHs in Jamaica tended to spend more on food, education and children's clothing, and less on alcohol and tobacco. However, it is important to note that none of these papers estimated the share of resources that is allocated to the different members of the household. More recent literature such as Gaiha and Kulkarni (2005), Klasen et al. (2015) and Liu et al. (2017) analyzed FHHs in Asia and Latin America. Again, these studies did not estimate actual resource shares of individual household members.

Within Jamaica's unique sociocultural context, we estimated and conducted a comparative analysis of children's resource shares in MHHs and FHHs using the modern household collective model developed by Dunbar et al. (2013) (DLP hereafter). We applied this model to a rotating panel constructed from the Jamaican Survey of Living Conditions (JSLC hereafter) for the period from 1990 to 2010. In terms of methodology, our study is also original since, to the best of our knowledge, this kind of collective model has not yet been used with panel data. Using such data allowed us to control (at least partially) for possible endogeneity in our model by accounting for time-invariant unobserved heterogeneities within households. We did this by incorporating Mundlak's (1978) approach to panel data into the DLP model. In particular, we included time averages of all time-varying covariates (also known as Mundlak terms) in our regression model to control for household time invariant effects. Similar to Roberts and Taylor (2017) who also accounted for individual fixed effects in the context of intra-household commuting choices, we implemented our model using a seemingly unrelated regression model.

\section{Theoretical Framework}

Traditionally in economics, households are known as unitary models and are depicted as single decision making units even if they are comprised of very different models 
(Vermeulen 2002a). Importantly, this approach assumes that household preference, and hence expenditure choices, coincide with individual preferences. However, as a response to the general empirical rejection of the unitary model, the collective model was pioneered by Chiappori (1988). More specifically, a collective model recognizes that households are made up of different individuals, each characterized by the individual members. Moreover, a collective model assumes that these individuals collectively make Pareto-efficient decisions, i.e., where, ceteris paribus, no decision could make one individual better off without making at least one other household member worse off. Arguably, this approach is much more suited to investigate questions of differences in intra-household resource allocation.

In this study we used the DLP version of the collective household model which estimates resource shares of individual household members with a particular focus on the shares of children. Notably, in many earlier versions of the collective model, children were not treated as individuals who have preferences of their own, but rather as public goods for parents or as a household characteristic (see Blundell et al. 2005 for example). As argued by DLP, children are unique members of the household because in most cases they are unable to make a choice as to which household to belong to, may find it difficult to leave in strenuous circumstances, and do not contribute to household income substantially. Hence, they are likely to be the most vulnerable individuals within a household.

Assuming Price Invariant Generalized Logarithmic preferences (Muellbauer 1976) for household members, the model takes the following form, where we for simplicity suppress time subscripts and other determining demographic factors:

$$
W_{a j}(y)=\eta_{a j}\left(\delta_{a j}+\beta_{a j} \ln \eta_{a j}\right)+\eta_{a j} \beta_{a j} \ln y
$$$$
W_{c j}(y)=j \eta_{c j}\left(\delta_{c j}+\beta_{c j} \ln \eta_{c j}\right)+j \eta_{c j} \beta_{c j} \ln y
$$

for $i=a, c$ and $j=1,2,3,4$. The subscripts $i$ and $j$ represent individual and household types, respectively. Household types are determined by the size of the household; $j=1,2,3,4$ indexes households with one, two, three, and four children, respectively. Each household consists of two individual types: adults denoted by $i=a$, and children denoted by $i=c . W_{i j}$ represents the household budget share of individual $i$ 's private assignable good, $y$ total household expenditure, $\eta_{i j}$ the resource share of individual $i$ in household type $j$, and $\delta_{i j}$ and $\beta_{i j}$ are the intercept preference parameters and the latent slope preference parameters, respectively.

Two important restrictions allow one to identify Equation (1). First, resource shares $\eta_{i j}$ and household expenditures $y$ are assumed to be independent of each other. While this may seem like a rather restrictive assumption, Menon et al. (2012) and Cherchye et al. (2012), using Italian and Dutch data, respectively, found that it holds. ${ }^{4}$ Moreover, other variables that are highly correlated with household expenditures, such as income or wealth, can be used instead. The second identifying assumption involves invoking at least one of the following semi-parametric restrictions on the individual budget-share equations, which are interpretable as Engel curves (Lewbel and Pendakur 2008). The SAP (Similar Across People) restriction assumes that the preferences of individuals within households with a particular number of children are similar in certain limited ways. This implies, for instance, that individuals in one-child households have similar tastes. As a consequence, $\beta_{i j}$ is specified as $\beta_{j}$ for all $i$. The SAT (Similar Across Types) restriction, in contrast, supposes that the preferences of individuals are similar across household types. For example, under the SAT fathers would have similar preferences irrespective of the number of the children they have. In correspondence, $\beta_{i j}$ is denoted as $\beta_{i}$ for all $j$. If one assumes both SAP and SAT, then $\beta_{i j}$ becomes $\beta$ for all $i$ and $j$. It is important to note, that unlike DLP, we were unable to estimate the share of men and women separately as we did not have separate private assignable goods for men and women in our data set. This was, however, not a huge loss in our context since our main focus was to compare children's resource shares in MHHs to children's resource shares in FHHs.

\section{Data}

The Jamaican Survey of Living Conditions (JSLC) is a nation-wide survey that was introduced in 1988 to monitor the economic welfare of households within the country. Since 1990 the survey has been carried out on an annual basis (except for 2011 when no data was collected). The JSLC is tagged to the national Labour Force Survey (LFS hereafter) which is carried out using a one-half panel design. This means that half of the households from a previous round of the LFS, and by extension the JSLC, were included in the current sample as long as the master frame was not changed. This one-half panel design enabled us to construct a rotating panel of households for the following years: 1990-1992, 1993-1994, 1995-1996, 1997-1998, 1998-2000, 2002-2003, 2004-2006, and 2007-2010. We followed Handa's (2008) procedure in matching households across different rounds of the JSLC. More specifically, we constructed a unique household identifier that was used to match households across years. Before households were

\footnotetext{
${ }^{4}$ In order to test this assumption one would need information on how much of total expenditure is spent on children, which, unfortunately, the Jamaican data set does not provide, so that we cannot explicitly test this.
} 
matched, we verified that the gender of the household head had not changed, that his/her age had not changed by more than 2 years, and that the household size did not change by more than 2 people. Using this criteria, and similar to Handa (2008), we were able to match about $70 \%$ of the households across years. Our match rates were slightly higher in later years of the sample period. We used monthly Consumer Price Indices from the Bank of Jamaica to deflate all monetary values with December 2006 as the base value.

The JSLC's core modules included health, education, consumption, nutrition, and housing. For most years an additional module was included that focused on specific subjects such as remittances, coping strategies, ageing and employment. Adult's and children's clothing and footwear were used as the private assignable goods because expenditures on these goods were observed separately in the JSLC.

We restricted our sample to monogamous nuclear households. This was done for three reasons. First, the private assignable goods that were available from our data set allowed individual resource shares to be easily identified in these kinds of households. Taking this a step further, we also excluded households with children older than 13 to ensure that clothing and footwear could not be shared between adults and children within the same household since these goods were crucial for the identification of resource shares. In addition to this, the JSLC treated children older than 13 as adults. Therefore, they were able to enter the labour market freely. Second, restricting our sample to nuclear monogamous households ensured that the structure of MHHs and FHHs were as similar as possible and hence made them more comparable. This also meant that conclusions drawn from the comparative analysis were likely to be more robust and reliable. Third, and most importantly, it significantly reduced the bias that may have been present in the identification of household heads. These biases were usually greater in extended family households where the oldest male adult assumed the position of the household head even if he was not the individual responsible for the upkeep and maintenance of the family (Handa 1994). Finally, one should note that we also included partnered FHHs in our sample because they enabled us to determine whether the presence of a male adult in a FHH adversely affected the resource shares children receive when compared to single-mother households.

\section{Empirical Framework}

In an attempt to adjust the original DLP model to fit a panel data set where we were able to follow households over time, as we used here, we incorporated Mundlak's (1978) approach as this enabled us to control for unobserved heterogeneities at the household level which did not vary with time. Importantly accounting for these household fixed effects allowed us to control (at least partially) for possible endogeneity that may have existed in the original DLP model. In contrast, DLP addressed these endogeneity issues in their original study by using instrumental variables. In cases, such as ours, where similar viable instrumental variables could not be obtained from the available data set, controlling for household heterogeneities in a panel-data setting is an alternative route researchers can take to control for possible endogeneity in the DLP model.

One can consider the Mundlak (1978) framework using the simple unobserved effects model below:

$y_{s t}=x_{s t} \psi+v_{s}+u_{s t}$

where $s=(1,2, \ldots, S)$ denotes the cross-sectional unit (which is the household in our case), and $t=(1,2, \ldots, T)$ denotes the time period. $x_{s t}$ is a matrix of observable explanatory variables which may change across both $s$ and $t$, or across $s$ but not $t$, or across $t$ but not $s . \psi$ represents the matrix of coefficients, $v_{s}$ denotes the unobserved heterogeneities which are time-invariant and $u_{s t}$ represents idiosyncratic disturbances which vary across $s$ and $t$.

The key concern with $v_{s}$ in this kind of setup is whether or not it is correlated with $x_{s t}$. If the two terms are correlated, a fixed effects estimation approach is appropriate. However, standard fixed effects estimation can be difficult to carry out in non-linear models, such as the DLP framework. Under such circumstances, a correlated random effects (CRE) framework such as the Mundlak approach can provide a useful alternative. One should note that the difference between this framework and the pure fixed effects approach is that with CRE, the relationship between $v_{s}$ and $x_{s t}$ is modelled in a very specific way (Wooldridge 2010, p. 286). More specifically, Mundlak (1978) allows $v_{s}$ to depend on time averages or panel-level averages of the observed covariates $\left(x_{s t}\right)$ that vary over time so that:

$v_{s}=\bar{x}_{s} \pi+w_{s}$

where $\bar{x}_{s}$ denotes the time averages of time-varying covariates in $x_{s t}, \pi$ is the matrix of coefficients, and $w_{s}$ is the error term which is independently and identically distributed. These time averages or panel-level averages are usually referred to as Mundlak terms. Substituting Eq. (3) into Eq. (2) gives the following expanded model:

$y_{s t}=x_{s t} \psi+\bar{x}_{s} \pi+w_{s}+u_{s t}$.

It is important to note that the error term in Eq. (4) is a sum of $w_{s}$ and $u_{s t}$. A generalized least squares (GLS) estimation of Eq. (4) is efficient and produces an estimator of $\psi$ that equals the fixed effects estimator (Cameron and Trivedi 2005, p. 719).

We incorporated this framework into the DLP model by including Mundlak terms in the intercept preference 
parameters $\left(\delta_{i j}\right)$, the slope preference parameters $\left(\beta_{i j}\right)$, and the resource share functions $\left(\eta_{i j}\right)$ of Equation (1). Then we estimated Equation (1) using an iterated feasible generalized non-linear least squares estimation method within a nonlinear seemingly unrelated model framework. This produced the fixed effects estimator for the explanatory variables that varied across $s$ and $t$. Due to the complicated nature of the error term in this model, we obtained fully robust inferences by using an unrestricted variance-covariance matrix. ${ }^{5}$

Based on our data set, we included the following demographic variables in our model: the region of residence (rural area, other urban area, and the Kingston Metropolitan Area as the reference category), the age of the man, the age of the woman, the minimum age of the children in the household, the number of children aged less than three, the proportion of male children, dummies indicating whether the man and the woman have completed tertiary education, a dummy indicating whether the household receives remittances or other support from family and friends elsewhere in Jamaica, a dummy indicating whether the household receives any form of public assistance or poor relief, and a dummy indicating whether a male-adult is resident in a FHH. These demographic variables were included in both the resource share functions $\left(\eta_{i j}\right)$ and the preference functions $\left(\delta_{i j}\right.$ and $\left.\beta_{i j}\right)$ of Equation (1) and hence could not be described as distribution factors. This term in the literature is used to describe variables that affect resource shares but do not affect the preferences of individuals in the household. In some previous versions of the collective model, distribution factors played a vital role in identifying changes in resource shares (see Chiappori and Ekeland 2009; Browning et al. 1994; Chiappori et al. 2002; Vermeulen 2002b for examples of such studies). However, the validity of distribution factors can be difficult to test. Fortunately, the DLP model does not need distribution factors in the identification of the levels of individual resource shares within the household.

Following DLP, we estimated our log-linear Engel curves (Equation (1)) using an iterated non-linear seemingly unrelated regression model. We allowed the errors to be correlated across the two equations. To construct the Mundlak terms we calculated time averages or panel-level averages of all demographic variables that changed across time. Apart from variables indicating the region of residence, all other demographic variables varied across time. Hence, we constructed Mundlak terms for 10 out of 12 demographic covariates.

Let $d=(d 1, d 2, \ldots, d 12)$ be a vector of all the demographic variables, let $g=(g 1, g 2, \ldots, g 10)$ be a vector of the Mundlak terms and $b=(b 1, \ldots, b 4)$ be a vector of four

\footnotetext{
5 We implemented this in Stata using the "cluster" option instead of the "robust" option.
}

dummy variables, each indicating a household type $j$. The vector $b$ played the role of the constant for each household type in $\eta_{i j}, \delta_{i j}$, and $\beta_{i j}$. For the baseline model, $\eta_{i j}$ and $\delta_{i j}$ were specified as linear in $b$ and $d$ for a maximum of 16 coefficients each. As already mentioned, $\beta_{i j}$ was specified according to the semi-parametric restriction imposed on the Engel curves. For SAP, $\beta_{i j}$ was specified as linear in $b$ and $d$ for a maximum of 16 coefficients. For SAT, $\beta_{i j}$ was specified as linear in a constant and $d$ for each of the 2 individual types for a maximum of 26 coefficients. When both SAP and SAT were imposed, $\beta_{t s}$ was specified as linear in a constant and $d$ for a maximum of 13 coefficients.

The parameters $\eta_{i j}$ and $\delta_{i j}$ were specified as linear in $b$, $d$, and $g$ for a maximum of 26 coefficients each. For SAP, $\beta_{i j}$ was specified as linear in $b, d$, and $g$ for a maximum of 26 coefficients. For SAT, $\beta_{i j}$ was specified as linear in a constant, $d$, and $g$ for each of the 2 individual types for a maximum of 46 coefficients. When both SAP and SAT are imposed, $\beta_{t s}$ was specified as linear in a constant, $d$, and $g$ for a maximum of 23 coefficients. ${ }^{6}$

\section{Results and Discussion}

\section{Summary Statistics}

Our final sample consisted of 479 MHHs of a couple with one to four children, 304 FHHs of a single mother with one to four children, and 159 FHHs of a couple with one to four children. These nuclear monogamous households made up $46 \%$ of total households in the Jamaican SLC surveys. According to Rosenhouse (1989), MHHs usually indicate an intact couple whereas FHHs usually represent a single female or a female in some sort of consensual union. In our sample, we found that all partnered households (whether MHH or FHH) indicated an intact couple in that the couple was either married or had a common law relationship. About $58 \%$ of the couples in the MHHs were in a common law relationship, while $42 \%$ are married. Similarly, $79 \%$ of the couples in partnered FHHs were in a common law relationship while $21 \%$ are married. The higher percentage of common law relationships among partnered FHHs was not surprising as one of the social requirements for marriage for a man in Jamaican culture was to own a house (Handa 1996a). It is therefore plausible that in these partnered FHHs the women tended to own the houses in which they lived. It could also be

\footnotetext{
${ }^{6}$ We were unable to add year dummies as our models did not converge due to relatively small sample sizes. We attempted to include period dummies and found that our results did not change significantly for the models that do converge. This was probably due to the fact that we followed households for just 2 years on average.
} 
Table 1 Summary statistics for sample by family type

\begin{tabular}{|c|c|c|c|c|}
\hline & \multirow{2}{*}{$\begin{array}{l}\text { MHHs } \\
\text { Couples with children }\end{array}$} & \multicolumn{2}{|l|}{ FHHs } & \multirow[t]{2}{*}{ All } \\
\hline & & Couples with children & $\begin{array}{l}\text { Single mothers with } \\
\text { children }\end{array}$ & \\
\hline \multicolumn{5}{|l|}{ General characteristics } \\
\hline Men's age & $\begin{array}{l}36.2 \\
(8.51)\end{array}$ & $\begin{array}{l}34.9 \\
(7.62)\end{array}$ & - & $\begin{array}{l}35.9 \\
(8.34)\end{array}$ \\
\hline Women's age & $\begin{array}{l}31.3 \\
(8.28)\end{array}$ & $\begin{array}{l}30.5 \\
(6.78)\end{array}$ & $\begin{array}{l}32.3 \\
(7.86)\end{array}$ & $\begin{array}{l}31.5 \\
(7.96)\end{array}$ \\
\hline Men's tertiary education dummy & $\begin{array}{l}0.09 \\
(0.29)\end{array}$ & $\begin{array}{l}0.02 \\
(0.15)\end{array}$ & - & $\begin{array}{l}0.08 \\
(0.27)\end{array}$ \\
\hline Women's tertiary education dummy & $\begin{array}{l}0.10 \\
(0.29)\end{array}$ & $\begin{array}{l}0.06 \\
(0.24)\end{array}$ & $\begin{array}{l}0.08 \\
(0.28)\end{array}$ & $\begin{array}{l}0.09 \\
(0.28)\end{array}$ \\
\hline Proportion of male children & $\begin{array}{l}0.51 \\
(0.40)\end{array}$ & $\begin{array}{l}0.51 \\
(0.39)\end{array}$ & $\begin{array}{l}0.52 \\
(0.41)\end{array}$ & $\begin{array}{l}0.51 \\
(0.40)\end{array}$ \\
\hline Average age of children & $\begin{array}{l}5.6 \\
(3.06)\end{array}$ & $\begin{array}{l}6.1 \\
(2.86)\end{array}$ & $\begin{array}{l}7.0 \\
(2.88)\end{array}$ & $\begin{array}{l}6.1 \\
(3.04)\end{array}$ \\
\hline Rural household dummy & $\begin{array}{l}0.55 \\
(0.50)\end{array}$ & $\begin{array}{l}0.48 \\
(0.50)\end{array}$ & $\begin{array}{l}0.40 \\
(0.49)\end{array}$ & $\begin{array}{l}0.49 \\
(0.50)\end{array}$ \\
\hline Weekly expenditure in $\mathrm{J} \$$ & $\begin{array}{l}8569.30 \\
(6852.48)\end{array}$ & $\begin{array}{l}6868.08 \\
(3686.95)\end{array}$ & $\begin{array}{l}6042.24 \\
(5218.34)\end{array}$ & $\begin{array}{l}7519.14 \\
(6088.26)\end{array}$ \\
\hline \multicolumn{5}{|l|}{ Budget shares } \\
\hline Adult's clothing and footwear & $\begin{array}{l}0.056 \\
(0.041)\end{array}$ & $\begin{array}{l}0.057 \\
(0.037)\end{array}$ & $\begin{array}{l}0.055 \\
(0.046)\end{array}$ & $\begin{array}{l}0.056 \\
(0.042)\end{array}$ \\
\hline Children's clothing and footwear & $\begin{array}{l}0.041 \\
(0.030)\end{array}$ & $\begin{array}{l}0.046 \\
(0.031)\end{array}$ & $\begin{array}{l}0.057 \\
(0.038)\end{array}$ & $\begin{array}{l}0.047 \\
(0.034)\end{array}$ \\
\hline Food & $\begin{array}{l}0.491 \\
(0.194)\end{array}$ & $\begin{array}{l}0.543 \\
(0.162)\end{array}$ & $\begin{array}{l}0.516 \\
(0.187)\end{array}$ & $\begin{array}{l}0.507 \\
(0.188)\end{array}$ \\
\hline Housing & $\begin{array}{l}0.111 \\
(0.110)\end{array}$ & $\begin{array}{l}0.093 \\
(0.112)\end{array}$ & $\begin{array}{l}0.124 \\
(0.123)\end{array}$ & $\begin{array}{l}0.113 \\
(0.115)\end{array}$ \\
\hline Transportation and communication & $\begin{array}{l}0.114 \\
(0.107)\end{array}$ & $\begin{array}{l}0.103 \\
(0.094)\end{array}$ & $\begin{array}{l}0.085 \\
(0.077)\end{array}$ & $\begin{array}{l}0.103 \\
(0.097)\end{array}$ \\
\hline Health & $\begin{array}{l}0.020 \\
(0.024)\end{array}$ & $\begin{array}{l}0.017 \\
(0.025)\end{array}$ & $\begin{array}{l}0.022 \\
(0.027)\end{array}$ & $\begin{array}{l}0.020 \\
(0.025)\end{array}$ \\
\hline Education & $\begin{array}{l}0.040 \\
(0.071)\end{array}$ & $\begin{array}{l}0.037 \\
(0.043)\end{array}$ & $\begin{array}{l}0.051 \\
(0.059)\end{array}$ & $\begin{array}{l}0.043 \\
(0.064)\end{array}$ \\
\hline Vices & $\begin{array}{l}0.012 \\
(0.033)\end{array}$ & $\begin{array}{l}0.013 \\
(0.032)\end{array}$ & $\begin{array}{l}0.006 \\
(0.026)\end{array}$ & $\begin{array}{l}0.010 \\
(0.031)\end{array}$ \\
\hline Sample size (households) & 479 & 159 & 304 & 942 \\
\hline
\end{tabular}

Standard deviations are in parentheses

an indication that the man in the household was unable to bear the economic burden of maintaining the household and hence had very little bargaining power in the household (Handa 1996a). The single-mother FHHs in our sample suited the definition of FHHs found in Rosenhouse (1989) to a large extent; only $9 \%$ of them were married or engaged in a common law relationship. Eighty seven per cent of them were either single or engaged in a visiting relationship, while $4 \%$ of them reported to be in no sort of union. In total, our sample was made up of 942 households and 2043 observations (on average, each household was followed for 2 two years).

We present summary statistics according to the different household categories in Table 1. The men in our sample were generally older than the women for all partnered households. On average, women were more likely than men to attend tertiary education. According to Reddock (2009), the female share of tertiary education in Jamaica was about $70 \%$. This was because in Jamaica the pecuniary returns associated with additional education was much larger for 
women than for men (Handa 1996c; Boxill and Quarless 2005). Men, on the other hand were more likely to pursue vocational training after their secondary school education (STATIN and PIOJ 2014). Similar to Handa (1996c), we found that FHHs were more likely to live in urban households. It was also clear from weekly expenditure values that on average MHHs were richer than FHHs.

Turning to the budget shares of goods which represent the weights which each household gives to each of these goods, one sees that all households spent most of their income on food, housing, and transportation and communication. With regard to the private assignable goods, the share of adult clothing and footwear was roughly equal across all household categories. ${ }^{7}$ In other words, equal weights were given to adult clothing and footwear in each household category. On the other hand, FHHs, and especially single-mother households, tended to put a higher weight on children's clothing and footwear than MHHs, although MHHs may have spent more in absolute terms on children's clothing and footwear due to higher overall expenditure levels. Single-mother households were more likely to have highest budget shares for other child-related goods such as health and education, and the lowest budget shares for vices (alcohol and tobacco), which were more adult-specific. The share of vices doubled in all partnered households and was highest in partnered FHHs where the male adult was more likely to be idle and not involved in any economic activity. This could be seen as preliminary evidence in support of Duflo (2003), Duflo and Udry (2004), and Caiumi and Perali (2015), who showed that women's preferences tended to be more child-friendly. On average, we also found that single mothers tended to spend more on housing compared to other households. This may be because a larger proportion of single-mother households lived in urban areas where housing is more expensive.

\section{Resource Share Estimates}

In this section, we present the main empirical findings of our paper. Both the baseline model and the model with Mundlak terms were carried out for all MHHs, all FHHs, and also for single-mother households only. For each of the three household categories, - MHHs, FHHs, and single mother households - we experimented with imposing the SAP restriction alone, the SAT restriction alone, and both SAP and SAT restrictions. We found the SAT restriction to be the weakest identifying assumption for all household categories. As explained by DLP, one may need a very large sample size to produce precise estimates when the SAT restriction alone is imposed. In this section, we focus on estimates from

\footnotetext{
7 The omitted category that would have made the total sum of shares equal to one are all other goods not listed in the table.
}

imposing both restrictions, because for the most part these estimates are the most precise. Also, upon testing the validity of the SAT restriction given the SAP restriction, we conclude that the SAT restriction holds in our data set once the SAP restriction has already been imposed. ${ }^{8}$

Table 2 presents the estimates of the resource share functions $\left(\eta_{i j}\right)$ when both SAP and SAT were imposed as identifying restrictions for the the three household categories. Following DLP, the household size dummies outlined the resource shares for adults, children, and each child in a reference household. In our case, this household lived in the Kingston Metropolitan Area, did not receive any support from friends and family within or outside the country, and did not receive any public assistance or poor relief. All adults in this household had not completed tertiary education and all children within the household are girls.

Generally, a relatively smaller share of resources was allocated to children in MHHs. In MHHS, children's resource shares ranged from 31 to $8 \%$ per child as the number of children in the household increased, while they ranged from 52 to $19 \%$ per child in all FHHs and from 56 to $21 \%$ per child in single-mother households. This can be attributed to a number of reasons. First, while all MHHs in our sample consisted of 2 adults, close to $70 \%$ of the FHHs were composed of a single adult. Although couples seemed to enjoy large scale economies (when one compared the estimates for MHHs and single-mother households for instance), children appeared to benefit with regards to resource shares from having just one adult present in the household. Second, this could indicate that the preferences of women in Jamaica were more child-related and hence, as household heads, they were able to allocate a larger share of resources to the children. We also noticed that, unlike MHHs, the total share of resources for adults consistently declined with the number of children in FHHs and single-mother households. For all three categories of households, the per-capita share for children decreased substantially as the number of children in the household increases. Again, this could be an indication that large scale economies to consumption exist among the children as well.

With regard to the region of residence, children were generally worse off in terms of resource shares if they lived in the Kingston Metropolitan Area. Up to 15\% of resource

\footnotetext{
${ }^{8}$ Following DLP, we do this by first estimating our model imposing only the SAP restriction. We then test the null hypothesis that the coefficients on the household size dummies inside $\beta_{i j}$ are statistically equal using a Wald test as this is equivalent to imposing the SAT restriction. For all three household categories, we find that this null hypothesis cannot be rejected with p-values of $0.2715,0.3729$, and 0.3017 for MHHs, FHHs, and single-mother households respectively. Therefore, we conclude that the SAT restriction is valid once the SAP restriction has already been imposed.
} 
Table 2 Resource share estimates for Jamaican households

\begin{tabular}{|c|c|c|c|c|c|c|c|}
\hline \multirow[t]{2}{*}{ Household characteristic } & \multirow[t]{2}{*}{ Individual type } & \multicolumn{2}{|c|}{ Male-headed households } & \multicolumn{2}{|c|}{$\begin{array}{l}\text { Female-headed house- } \\
\text { holds }\end{array}$} & \multicolumn{2}{|c|}{$\begin{array}{l}\text { Single-mother house- } \\
\text { holds }\end{array}$} \\
\hline & & Estimate & StdErr & Estimate & StdErr & Estimate & StdErr \\
\hline \multirow[t]{3}{*}{ One child } & Adults & $0.688 * *$ & 0.083 & $0.479 * *$ & 0.069 & $0.441 * *$ & 0.068 \\
\hline & Children & $0.312 * *$ & 0.083 & $0.521 * *$ & 0.069 & $0.559 * *$ & 0.068 \\
\hline & Each child & $0.312 * *$ & 0.083 & $0.521 * *$ & 0.069 & $0.559 * *$ & 0.068 \\
\hline \multirow[t]{3}{*}{ Two children } & Adults & $0.636^{* *}$ & 0.086 & $0.416 * *$ & 0.073 & $0.412 * *$ & 0.076 \\
\hline & Children & $0.364 * *$ & 0.086 & $0.584 * *$ & 0.073 & $0.588 * *$ & 0.076 \\
\hline & Each child & $0.182 * *$ & 0.043 & $0.292 * *$ & 0.035 & $0.294 * *$ & 0.038 \\
\hline \multirow[t]{3}{*}{ Three children } & Adults & $0.594 * *$ & 0.085 & $0.416 * *$ & 0.090 & $0.410 * *$ & 0.088 \\
\hline & Children & $0.406 * *$ & 0.085 & $0.584 * *$ & 0.090 & $0.590 * *$ & 0.088 \\
\hline & Each child & $0.135 * *$ & 0.028 & $0.195 * *$ & 0.030 & $0.197 * *$ & 0.029 \\
\hline \multirow[t]{3}{*}{ Four children } & Adults & $0.684 * *$ & 0.105 & $0.261 * *$ & 0.098 & 0.150 & 0.105 \\
\hline & Children & $0.316^{* *}$ & 0.105 & $0.739 * *$ & 0.098 & $0.850 * *$ & 0.105 \\
\hline & Each child & $0.079 * *$ & 0.026 & $0.185 * *$ & 0.025 & $0.213 * *$ & 0.026 \\
\hline \multirow[t]{2}{*}{ Other urban areas } & Adults & $-0.081 *$ & 0.038 & $-0.109 * *$ & 0.039 & $-0.147 * *$ & 0.049 \\
\hline & Children & $0.081^{*}$ & 0.038 & $0.109 * *$ & 0.039 & $0.147 * *$ & 0.049 \\
\hline \multirow[t]{2}{*}{ Rural areas } & Adults & $-0.144 * *$ & 0.032 & $-0.082 *$ & 0.041 & $-0.117 *$ & 0.048 \\
\hline & Children & $0.144 * *$ & 0.032 & $0.082 *$ & 0.041 & $0.117^{*}$ & 0.048 \\
\hline \multirow[t]{2}{*}{ Number of children $<3$ years old } & Adults & $0.119^{*}$ & 0.054 & $0.188 * *$ & 0.068 & $0.229 * *$ & 0.067 \\
\hline & Children & $-0.119^{*}$ & 0.054 & $-0.188 * *$ & 0.068 & $-0.229 * *$ & 0.067 \\
\hline \multirow[t]{2}{*}{ Proportion of male children } & Adults & 0.103 & 0.110 & $-0.152 *$ & 0.086 & $-0.194 *$ & 0.089 \\
\hline & Children & -0.103 & 0.110 & $0.152 \dagger$ & 0.086 & $0.194 *$ & 0.089 \\
\hline \multirow[t]{2}{*}{ Head completed tertiary education } & Adults & $-0.113 \dagger$ & 0.063 & $0.249 * *$ & 0.055 & $0.211 * *$ & 0.065 \\
\hline & Children & $0.113 \dagger$ & 0.063 & $-0.249 * *$ & 0.055 & $-0.211 * *$ & 0.065 \\
\hline \multirow[t]{2}{*}{ Support from others (incl remittances) } & Adults & -0.003 & 0.035 & -0.062 & 0.038 & $-0.094 *$ & 0.043 \\
\hline & Children & 0.003 & 0.035 & 0.062 & 0.038 & $0.094 *$ & 0.043 \\
\hline \multirow[t]{2}{*}{ Public assistance } & Adults & $-0.167 \dagger$ & 0.091 & 0.001 & 0.087 & 0.005 & 0.085 \\
\hline & Children & $0.167 \dagger$ & 0.091 & -0.001 & 0.087 & -0.005 & 0.085 \\
\hline \multirow[t]{2}{*}{ Partner present in FHH } & Adults & - & - & $0.170 * *$ & 0.063 & - & - \\
\hline & Children & - & - & $-0.170 * *$ & 0.063 & - & - \\
\hline
\end{tabular}

Standard errors robust to all forms of heteroskedasticity. $\dagger \mathrm{p}<0.10,{ }^{*} \mathrm{p}<0.05,{ }^{*} \mathrm{p}<0.01,{ }^{*} * \mathrm{p}<.001$

shares were diverted from children to adults who lived in this area. This holds irrespective of the gender of the household head. However, the shares of children were highest in rural areas for MHHs and were highest in other urban areas for FHHs. Since the cost of living was likely to be higher in urban areas (especially the capital city) than in rural areas (Kurre 2003), parents in the Kingston Metropolitan Area tended to spend more on other goods such as housing and utilities. For instance, within our sample, households living in the Kingston Metropolitan Area allocated about 15\% of total expenditure to housing and utility bills on average, whereas rural households allocated only $8 \%$ of their total expenditure to housing and utility bills. One finds a similar trend for non-consumption goods such as insurance and the repayment of loans.

Another similarity that existed between MHHs and FHHs was that children's shares decreased substantially (by $12 \%$ to $23 \%$ ) as the number of children less than three years old increased within the household. Since, according to the National Academy of Sciences (2015) 95\% of all children in Jamaica were enrolled in school by their third birthday, this result may indicate that parents tended to spend a lot more on their children once they were enrolled in school. These school-related expenses included the cost of transportation to school, extra lessons, books, and tuition. Also the magnitude of this effect was higher in FHHs than in MHHs. This was not surprising because FHHs and single mothers in particular, tended to invest more in the education of their children than MHHs. This may be due to the fact that in Jamaica the responsibility of child care fell predominantly on women. Hence, children were more likely to take care of their elderly mothers than their elderly fathers (Handa 1996a; Wyss 1999; Handa 1996c). 
Table 3 Average expenditure shares for FHHs

\begin{tabular}{|c|c|c|c|c|c|c|c|c|}
\hline & \multicolumn{2}{|c|}{$\mathrm{KMA}^{\mathrm{a}}$} & \multicolumn{2}{|c|}{ Other urban } & \multicolumn{2}{|l|}{ Rural } & \multicolumn{2}{|l|}{ All } \\
\hline & Head & Head & Head & Head & Head & Head & Head & Head \\
\hline & $\mathrm{TE}^{\mathrm{b}}$ & no TE & $\mathrm{TE}$ & no TE & $\mathrm{TE}$ & no TE & $\mathrm{TE}$ & no TE \\
\hline $\begin{array}{l}\text { Children's clothing } \\
\text { and footwear }\end{array}$ & 0.036 & 0.058 & 0.033 & 0.050 & 0.040 & 0.055 & 0.036 & 0.055 \\
\hline Housing & 0.213 & 0.139 & 0.147 & 0.112 & 0.126 & 0.083 & 0.174 & 0.109 \\
\hline Education & 0.053 & 0.049 & 0.086 & 0.044 & 0.040 & 0.042 & 0.056 & 0.045 \\
\hline
\end{tabular}

${ }^{a}$ KMA stands for Kingston Metropolitan Area.

${ }^{\mathrm{b}} \mathrm{TE}$ stands for tertiary education
The next covariate of interest related to gender bias within the household. Our results showed that single-mother households had a strong preference for male children; about 19\% of household resources were diverted from adults to children as the proportion of boys to girls rose. While this was true to a smaller extent in partnered FHHs, there appeared to be no such bias in MHHs. Studies such as DLP and Rose (1999) have also found some forms of gender inequality in favour of the boy child within the household. In patriarchal cultures like those of Eastern and Southern Asia, this is the common practice (Das Gupta et al. 2003). However, some anthropological and ethnographic studies, such as Sargent and Harris (1992), found that girls were generally preferred to boys in Jamaica, although they observed that often a special bond existed between mothers and sons. They based their arguments on evidence from the patterns of child abandonment, health, and adoption practices.

In spite of the fact that our results seem to conflict with studies from these other disciplines, we argue that by analysing gender bias in Jamaica from an economic perspective, our findings enrich the pool of knowledge that is already available on the subject. According to Handa (1996a), single mothers recognize that their older children can become assets to the household, in that they are able to contribute to household income. This then allows a single mother to be less dependent on her partner(s) and to maintain her independence. Hence, single mothers may prefer boys to girls because they are more likely to bring in income at an earlier age since they tend to enter the labour market earlier than girls do (Handa 1998). According to Boxill and Quarless (2005), the rate of absenteeism from school for boys is about three times that of girls because culturally boys are allowed to participate in the labour market at a very early age. Girls, on the other hand, usually stay in school and spend the rest of their time engaged in domestic activities (STATIN and PIOJ 2014).

The level of education that the household head attained was also an important factor in the household decisionmaking process. In MHHs, a man who had completed tertiary education tended to divert about $11.3 \%$ of resources from adults to children. Since previous evidence shows that women tend to be more concerned about the welfare of children, this finding could indicate that a more educated man is likely to be more willing to accommodate the preferences of his partner. Hence, similar to what Handa (1994) finds, children may also benefit from the presence of a female decision maker in the household who is not necessarily the head of the household.

In contrast to MHHs, a female head who had completed tertiary education tended to divert over $20 \%$ of household resources from children to adults. This was very surprising given that women are known to be more sensitive to the needs of their children. However, upon further investigation, we found that compared to their counterparts who had no tertiary education, female heads who had completed tertiary education tended to spend significantly more on housing and education and significantly less on children's clothing and footwear. This is evident in Table 3 which presents the average expenditure shares of these goods for female heads who have completed tertiary education and those who have not. These average values are also presented separately for each region of residence. From this table, it is clear that these findings are true particularly in the Kingston Metropolitan Area. Although housing is not seen as a typical child-related good, it may very well be in the Jamaican context. According to the World Bank (2004, pp. 45, 46), urban poverty in Jamaica is associated with vices such as crime and violence. Hence, especially in the KMA, high-income-earning female heads who have completed tertiary education (Boxill and Quarless 2005) tended to move into more decent, respectable, and often gated communities where housing tends to be very expensive in order to provide a safer and more nurturing environment for their children. These women also tended to send their children to private primary schools which are very costly (Heyneman and Stern 2014). We can therefore conclude that, even though all female heads care about their children's needs, their spending patterns may differ depending on their level of education (a variable which was highly correlated to her level of income) and their region of residence. Accordingly, it may be profitable in certain scenarios to analyze expenditure shares of other goods that are not traditionally known to be child-related. It is worth noting 
that these findings featured prominently in FHHs and not in MHHs because females in Jamaica were more likely to complete tertiary education and were also more likely to live in urban areas (STATIN and PIOJ 2014; Handa 1996c).

Support that a household in Jamaica receives from external sources in monetary form or in the form of goods and services usually comes in two forms: support received from family and friends living elsewhere in Jamaica or in another country and public assistance or poor relief from the government (including food stamps, school feeding programme, and $\mathrm{PATH}^{9}$ ). From Table 2, our results showed that public assistance increased the shares of children in MHHs by almost $17 \%$, whereas support received from family and friends (including remittances) led to a rise in children's resource shares by $9.4 \%$ in single-mother households. For single-mother households, the most likely reason for this is the common practice of child fostering in Jamaica, where children are sent to live with a member of the extended family or a friend. According to Wyss (1995), in 1989 more than half of Jamaican children did not live with their biological fathers, about a quarter did not live with their biological mothers, and about one-fifth lived apart from both parents. These biological parents usually send money and/or goods to help with the upkeep of their children. In addition to this, remittances are becoming more and more important in Jamaica because of the increase in emigration of adults (especially the male adult) to other countries to look for better employment (Massiah 1982). As stated by Stephenson and Wilsker (2016), in 2009 Jamaica was the 14th most reliant country on remittances in the world, with remittances comprising close to $15 \%$ of the country's GDP. This reliance of single-mother households on remittances and other forms of support from family and friends may cause them to be more vulnerable to economic and social shocks since these sources of income are relatively less stable (Benfield 2010).

Last but not least, we found that the presence of a male adult in a FHH reduced the share of children by $17 \%$. As already indicated, this means that children who lived with single mothers tend to have higher resource shares than children who live in partnered FHHs. This could be due to the fact that an unpartnered female head is able to fully implement her preferences without having to bargain with a man. It is however important to note that, children may benefit both socially and emotionally from the guidance, discipline, and support that a male adult in the household provides (Handa 1994). Unfortunately, our study is unable to take intangible benefits such as these into account.

\footnotetext{
9 PATH is an acronym for the Programme for Advancement through Health and Education. This programme is a conditional cash transfer programme that was created in 2001 and is aimed at increasing the welfare of children in poor households through human capital development.
}

\section{Conclusion}

With the increase in the incidence of FHHs in the developing world, investigating the nature of resource share allocation in these households has become crucial for the development and effective targeting of redistribution programmes. So far, most studies on household decision-making have focused on the traditional MHHs consisting of a couple with children. This study contributes to the literature by carrying out a comparative study of children's resource shares in MHHs and FHHs (including single-mother households) using a collective household model developed by Dunbar et al. (2013). We extend this model by incorporating Mundlak's (1978) approach. The extended model is then applied to a rotating panel of Jamaican households covering the period between 1990 and 2010. Using a panel data set allows us to account for unobserved household heterogeneities that are constant over time, thereby providing an alternative route to dealing with possible endogeneity that may be present in the DLP model.

We find that in Jamaica the gender of the household head is an important determinant of the final outcome. In particular, our findings show that the shares of children are substantially higher in FHHs (especially in single-mother households) than in MHHs, where children in single-mother households receive $56 \%$ to $85 \%$ of household resources, while children in MHHs receive only $31 \%$ to $41 \%$. In fact, children may be better off in single-mother households than in partnered FHHs as a male-adult tends to divert about $17 \%$ of household resources from children to adults in partnered FHHs. Hence, children in relatively poor single-mother households may be compensated by the higher shares they receive and thus may not necessarily be worse off when compared to children in MHHs or partnered FHHs. We also find a strong preference for the boy child in FHHs. This may result from the fact that boys are more likely to contribute significantly to future household income as they tend to enter the labour market at an earlier age compared to girls (STATIN and PIOJ 2014). We also show that the spending patterns of female heads differ depending on their level of education and their region of residence. More specifically, even though empirical evidence suggests that women tend to care more about their children's needs, their preferences may be expressed by spending on different kinds of goods depending on whether they have completed tertiary education and whether they live in an urban or rural area. Our findings also indicate that remittances and other support from family and friends affect the shares that children receive in single-mother households to a greater extent than public assistance. This may be due to the culture of child fostering in Jamaica. More generally, our study demonstrates that an increased cultural awareness of the region in question is 
a crucial component in understanding the nature of intrahousehold resource distribution in FHHs.

Finally, it must be noted that our analysis suffers from some drawbacks. First, we are unable to distinguish between men's resource shares and women's resource shares because of the unavailability of a separate private assignable good for men and women in the JSLC. Second, it is also impossible to check whether a child lives with his or her biological parents for a considerable number of years in the JSLC (from 1992 to 1999). Thirdly, it may very well be that females that have a stronger preference for children may choose to form their own households rather than become part of a male headed household. Whether it is these differences in preferences among females or some other feature peculiar to female headed household structures could not be determined from our analysis. All these additional pieces of information, however, would have greatly increased the depth of our understanding of intra-household resource allocation in FHHs vis-à-vis MHHs.

Funding Open Access funding provided by University of Bern. No funding was received for this study.

\section{Compliance with Ethical Standards}

Conflict of Interest The authors declare that they have no conflict of interest with regard to this study.

Ethical Approval There has been complete compliance with ethical standards in this study. Ethical approval was not required for this study.

Informed Consent Informed consent was not necessary for this study.

Open Access This article is licensed under a Creative Commons Attribution 4.0 International License, which permits use, sharing, adaptation, distribution and reproduction in any medium or format, as long as you give appropriate credit to the original author(s) and the source, provide a link to the Creative Commons licence, and indicate if changes were made. The images or other third party material in this article are included in the article's Creative Commons licence, unless indicated otherwise in a credit line to the material. If material is not included in the article's Creative Commons licence and your intended use is not permitted by statutory regulation or exceeds the permitted use, you will need to obtain permission directly from the copyright holder. To view a copy of this licence, visit http://creativecommons.org/licenses/by/4.0/.

\section{References}

Benfield, W. A. (2010). Poverty and perception in Jamaica: A comparative analysis of Jamaican households. Mona, Jamaica: UWI Press.

Blundell, R., Chiappori, P.-A., \& Meghir, C. (2005). Collective labor supply with children. Journal of Political Economy, 113(6), 12771306. https://doi.org/10.1086/491589.
Boxill, I., \& Quarless, R. (2005). The determinants of poverty among the youth of the Caribbean. Social and Economic Studies, 54(1), 129-160. https://doi.org/10.1590/S1413-81232009000100002.

Browning, M., Bourguignon, F., Chiappori, P.-A., \& Lechene, V. (1994). Income and outcomes: A structural model of intrahousehold allocation. Journal of Political Economy, 102(6), 1067-1096. https://doi.org/10.1086/261964.

Buvinic, M., \& Gupta, G. R. (1997). Female-headed households and female-maintained families: Are they worth targeting to reduce poverty in developing countries? Economic Development and Cultural Change, 45(2), 259. https://doi.org/10.1086/452273.

Caiumi, A., \& Perali, F. (2015). Who bears the full cost of children? Evidence from a collective demand system. Empirical Economics, 49(1), 33-64. https://doi.org/10.1007/s00181463-014-0854-2.

Cameron, C. A., \& Trivedi, P. K. (2005). Microeconometrics: Methods and applications. New York: Cambridge University Press.

Cherchye, L., De Rock, B., \& Vermeulen, F. (2012). Married with children: A collective labor supply model with detailed time use and intrahousehold expenditure information. American Economic Review, 102(7), 3377-3405. https://doi.org/10.1257/ aer.102.7.3377.

Chiappori, P.-A. (1988). Rational household labor supply. Econometrica: Journal of the Econometric Society, 56, 63-90.

Chiappori, P.-A., \& Ekeland, I. (2009). The microeconomics of efficient group behavior: Identification. Econometrica, 77(3), 763-799. https://doi.org/10.3982/ECTA5929.

Chiappori, P.-A., Fortin, B., \& Lacroix, G. (2002). Marriage market, divorce legislation, and household labor supply. Journal of Political Economy, 110(1), 37-73. https://doi. org/10.1086/324385.

Das Gupta, M., Jiang, Z., Li, B., Xie, Z., Woojin, C., \& Bae, H.-O. (2003). Why is son preference so persistent in East and South Asia? A cross-country study of China, India and the Republic of Korea. Journal of Development Studies, 40(2), 153-187. https:// doi.org/10.1080/00220380412331293807.

Duflo, E. (2003). Grandmothers and granddaughters: Old-age pensions and intrahousehold allocation in South Africa. The World Bank Economic Review, 17(1), 1-25. https://doi.org/10.1093/wber/ lhg013.

Duflo, E., \& Udry, C. (2004). Intrahousehold resource allocation in Côte d'Ivoire: Social norms, separate accounts and consumption choices (Working Paper No. 10498). National Bureau of Economic Research. Retrieved from http://www.nber.org/paper s/w10498https://doi.org/10.3386/w10498

Dunbar, G. R., Lewbel, A., \& Pendakur, K. (2013). Children's resources in collective households: Identification, estimation, and an application to child poverty in Malawi. American Economic Review, 103(1), 438-471. https://doi.org/10.1109/JPROC .2010.2070470.

Eggleston, E., Jackson, J., \& Hardee, K. (1999). Sexual attitudes and behavior among young adolescents in Jamaica. International Family Planning Perspectives, 25(2), 78-91. https://doi. org/10.2307/2991945.

Gaiha, R., \& Kulkarni, V. (2005). Anthropometric failure and persistence of poverty in rural India. International Review of Applied Economics, 19(2), 179-197. https://doi.org/10.1080/0269217050 0031711.

Handa, S. (1994). Gender, headship and intrahousehold resource allocation. World Development, 22(10), 1535-1547. https://doi. org/10.1016/0305-750X(94)90036-1.

Handa, S. (1996a). The determinants of female headship in Jamaica: Results from a structural model. Economic Development and Cultural Change, 44(4), 793. https://doi.org/10.1086/452245.

Handa, S. (1996b). Expenditure behavior and children's welfare: An analysis of female headed households in Jamaica. 
Journal of Development Economics, 50(1), 165-187. https://doi. org/10.1016/0304-3878(96)00008-9.

Handa, S. (1996c). Maternal education and child attainment in Jamaica: Testing the bargaining power hypothesis. Oxford Bulletin of Economics and Statistics, 58(1), 119-137. https://doi. org/10.1111/j.1468-0084.1996.mp58001006.x.

Handa, S. (1998). Are female-headed households time poor? Evidence from Jamaica. Social and Economic Studies, 47(4), 1-27.

Handa, S. (2008). Moving on up? The dynamics of poverty in Jamaica. (Keynote Address: 20th Anniversary Conference on the Jamaica Survey of Living Conditions).

Heyneman, S. P., \& Stern, J. M. (2014). Low cost private schools for the poor: What public policy is appropriate? International Journal of Educational Development, 35, 3-15. https://doi.org/10.1016/j. ijedudev.2013.01.002.

Jeynes, W. H. (2002). Examining the effects of parental absence on the academic achievement of adolescents: The challenge of controlling for family income. Journal of family and Economic Issues, 23(2), 189-210. https://doi.org/10.1023/A:1015790701554.

Johnson, F. C., \& Rogers, B. L. (1993). Children's nutritional status in female-headed households in the dominican republic. Social Science \& Medicine, 37(11), 1293-1301. https://doi. org/10.1016/0277-9536(93)90159-2.

Klasen, S., Lechtenfeld, T., \& Povel, F. (2015). A feminization of vulnerability? Female headship, poverty, and vulnerability in Thailand and Vietnam. World Development, 71, 36-53. https://doi. org/10.1016/j.worlddev.2013.11.003.

Kurre, J. A. (2003). Is the cost of living less in rural areas? International Regional Science Review, 26(1), 86-116. https://doi. org/10.1177/0160017602238987.

Lewbel, A., \& Pendakur, K. (2008). Estimation of collective household models with Engel curves. Journal of Econometrics, 147(2), 350-358. https://doi.org/10.1016/j.jeconom.2008.09.012.

Liu, C., Esteve, A., \& Trevino, R. (2017). Female-headed households and living conditions in Latin America. World Development, 90 , 311-328. https://doi.org/10.1016/j.worlddev.2016.10.008.

Louat, F., Grosh, M., \& van der Gaag, J. (1993). Welfare implications of female headship in Jamaican households. LSMS Working Paper No. 96, World Bank.

Mangiavacchi, L., Perali, F., \& Piccoli, L. (2014). Intrahousehold distribution in migrant-sending families (Working Papers No. 344). ECINEQ, Society for the Study of Economic Inequality. Retrieved from https://ideas.repec.org/p/inq/inqwps/ecineq2014-344.html.

Massiah, J. (1982). Female-headed households and employment in the Caribbean. Women's Studies International, 2, 7-16. https://doi. org/10.1016/j.worlddev.2016.10.008.

Massiah, J. (1983). Women as heads of households in the caribbean: Family structures and feminine status. Paris: UNESCO.

Menon, M., Pendakur, K., \& Perali, F. (2012). On the expendituredependence of children's resource shares. Economics Letters, 117(3), 739-742. https://doi.org/10.1016/j.econlet.2012.08.012.

Muellbauer, J. (1976). Community preferences and the representative consumer. Econometrica, 44(5), 979-999. https://doi. org/10.2307/1911540.

Mundlak, Y. (1978). On the pooling of time series and cross section data. Econometrica, 46(1), 69-85. https://doi.org/10.2307/19136 46.

National Academy of Sciences. (2015). Scaling program investments for young children globally: Evidence from Latin America and the Caribbean. Paper presented at the Forum on Investing in Young Children Globally.

Reddock, R. (2009). Gender and achievement in higher education. Paper presented at a Conference of the Association of Caribbean Higher Education Administrators (ACHEA), Hyatt Hotel, Port of Spain, Trinidad and Tobago, July 10, 2009.
Roberts, J., \& Taylor, K. (2017). Intra-household commuting choices and local labour markets. Oxford Economic Papers, 69(3), 734757. https://doi.org/10.1093/oep/gpw037.

Rose, E. (1999). Consumption smoothing and excess female mortality in rural India. Review of Economics \& Statistics, 81(1), 41-49. https://doi.org/10.1162/003465399767923809.

Rosenhouse, S. (1989). Identifying the poor: Is headship a useful concept?. LSMS Working Paper No. 58, World Bank.

Safa, H. I. (1998). Female-headed households in the Caribbean: Sign of pathology or alternative form of family organization the feminization of poverty here and abroad. Brown Journal of World Affairs, 5(2), 203-214. https://doi.org/10.1080/13545701.2018.1529417.

Safa, H. I. (2007). Globalization, inequality, and the growth of femaleheaded households in the Caribbean. In R. Bell \& V. Yans (Eds.), Women on their own: Interdisciplinary perspectives of being single (pp. 239-254). New Brunswick: Rutgers University Press.

Sargent, C., \& Harris, M. (1992). Gender ideology, childrearing, and child health in Jamaica. American Ethnologist, 19(3), 523-537. https://doi.org/10.1525/ae.1992.19.3.02a00060.

STATIN and PIOJ. (2014). Labour market transitions of young women and men in Jamaica. Work4Youth Publication Series No. 17, International Labour Office.

Stephenson, A., \& Wilsker, A. (2016). Consumption effects of foreign remittances in Jamaica. International Advances in Economic Research, 22(3), 309-320. https://doi.org/10.1007/s1129 4-016-9595-7.

Stuart, S. (1996). Female-headed families: A comparative perspective of the Caribbean and the developed world. Gender and Development, 4(2), 28-34. https://doi.org/10.1080/741922017.

United Nations. (2017). Household size and composition around the world 2017 - data booklet. United Nations. Department of Economic and Social Affairs, Population Division.

United Nations Development Programme. (2005). Human development report 2005: International cooperation at a cross roads: Aid, trade and security in an unequal world. New York: Oxford University Press for UNDP.

Vermeulen, F. (2002a). Collective household models: Principles and main results. Journal of Economic Surveys, 16(4), 533-564. https ://doi.org/10.1111/1467-6419.00177.

Vermeulen, F. (2002b). Collective household models: Principles and main results. Journal of Economic Surveys, 16(4), 533-564. https ://doi.org/10.1111/1467-6419.00177.

Wooldridge, J. M. (2010). Econometric analysis of cross section and panel data (2nd ed.). London: The MIT Press.

World Bank. (2004). The road to sustained growth in Jamaica. World Bank, Washington DC, USA. (A World Bank Country Study).

Wyss, B. (1995). Gender and the economic support of Jamaican households: Implications for children's living standards Unpublished Doctoral Dissertation. Amherst: University of Massachusetts.

Wyss, B. (1999). Culture and gender in household economies: The case of Jamaican child support payments. Feminist Economics, $5(2), 1-24$

Zeller, M., Schrieder, G., Von Braun, J., \& Heidhues, F. (1997). Rural finance for food security for the poor: Implications for research and policy (Vol. 4). Intl Food Policy Res Inst.

Publisher's Note Springer Nature remains neutral with regard to jurisdictional claims in published maps and institutional affiliations.

Theophiline Bose-Duker is a former $\mathrm{PhD}$ student, affiliated at the University of Birmingham, and currently working as a World Bank consultant. 
Michael Henry is a Senior Lecturer in Economics at the University of Birmingham.
Eric Strobl is a Professor of Economics at the University of Bern. 